\title{
Mutualistic symbiosis with ophiuroids limited the impact of the Deepwater Horizon oil spill on deep-sea octocorals
}

\author{
Fanny Girard*, Bo Fu, Charles R. Fisher \\ Department of Biology, The Pennsylvania State University, 208 Mueller Laboratory, University Park, Pennsylvania 16802, USA
}

\begin{abstract}
Deep-water corals form structurally complex biological habitats in the deep-sea that are generally associated with a diverse fauna. Yet, little is known about the effect of symbionts on coral resilience to natural or anthropogenic impacts. This study focused on the influence of the ophiuroid symbiont Asteroschema clavigerum on the resilience of its octocoral host Paramuricea biscaya after the Deepwater Horizon oil spill in the Gulf of Mexico. Corals were imaged between 2011 and 2014 at 4 sites, 3 of which were impacted by the spill. Each colony was digitized to quantify the impact on corals. We developed a method to define an area under the influence of ophiuroids for each coral colony. The level of total visible impact, as well as recovery, was then compared within and outside this area. For the majority of colonies, recovery from visible impact and hydroid colonization was negatively correlated with distance from the ophiuroid. Total visible impact was lower within the area influenced by ophiuroids, and branches within this area were more likely to recover. These results indicate that $P$. biscaya benefits from its association with $A$. clavigerum, likely through the physical action of ophiuroids removing material depositing on polyps, and perhaps inhibiting the settlement of hydroids. Although the beneficial role of the ophiuroids was demonstrated on corals affected by an oil spill, we suggest that these benefits would also extend to corals in environments exposed to natural sedimentation events, perhaps allowing the corals to live in environments where sedimentation would otherwise limit their survival.
\end{abstract}

KEY WORDS: Resilience - Anthropogenic impact · Cold-water coral · Alcyonacea - Euryalida · Paramuricea biscaya $\cdot$ Asteroschema clavigerum $\cdot$ Image analysis

\section{INTRODUCTION}

Deep-water corals form structurally complex habitats utilized by numerous associated organisms (Buhl-Mortensen \& Mortensen 2005, Roberts et al. 2006, Henry \& Roberts 2007). Many species use deep-sea corals as a nursery, a source of food, or as a substrate (Buhl-Mortensen \& Mortensen 2005, Etnoyer \& Warrenchuk 2007, Buhl-Mortensen et al. 2010, Mah et al. 2010, Baillon et al. 2012). Despite their importance, the interaction between deepwater corals, gorgonians in particular, and their associated fauna remains poorly understood.

${ }^{*}$ Corresponding author: fgirard@psu.edu
Commensalism (in which 1 organism benefits from the association without affecting its host) is the most common type of relationship hypothesized between invertebrates and octocorals (Buhl-Mortensen 2004). Several species of actinarians (Bronsdon et al. 1993), polychaetes, crustaceans (Buhl-Mortensen \& Mortensen 2004), and ophiuroids (Mosher \& Watling 2009) have been reported as obligate symbionts of deep-water octocorals. However, the nature of the relationship between octocorals and their closely associated invertebrates is often not apparent, and its consequences for the coral host are especially unclear.

() The authors 2016. Open Access under Creative Commons by Attribution Licence. Use, distribution and reproduction are unrestricted. Authors and original publication must be credited. 
The Euryalida, 1 of the 2 ophiuroid orders, includes 4 families: the Gorgonocephalidae (basket stars with branching arms), Asteronychidae, Euryalidae, and Asteroschematidae (snake stars with non-branching arms). Euryalid ophiuroids have been little studied, and knowledge on their feeding behavior, in particular, is sparse. However, several studies based on image and diet analyses imply that euryalids are predatory suspension feeders (Dearborn et al. 1986, Emson \& Woodley 1987, Fujita \& Ohta 1988, Grange 1991). Ophiuroids extend their arms to find zooplankton and can capture large live prey in an armloop (Warner 1982, Dearborn et al. 1986). Smaller prey and particles can be captured via several mechanisms: trapped by mucus-coated spines, trapped in mucus nets between spines, or directly captured by the tube feet and transferred to the mouth (Pentreath 1970, Warner 1982).

The majority of studies, from depths ranging from 5 to $1700 \mathrm{~m}$, suggest that euryalids associated with corals use their host primarily to get better access to zooplankton and particles suspended in the water column, hence benefiting from the association. Submersible and laboratory observations show that the euryalid brittle star Asteroschema tenue extends its arms in the water column at night while still clinging to the sea-whip gorgonian Ellisella barbadensis (Emson \& Woodley 1987). Similar observations have been made for Asteronyx loveni (Fujita \& Ohta 1988). These studies imply that the association between ophiuroids and their coral host has parasitic aspects (ophiuroids benefit from the association at the expense of their host) but is mainly a commensal association. Some authors have suggested that this association could be mutualistic (both partners benefit from the association). In addition to suspension feeding, the ophiuroid Astrobrachion constrictum uses its arms to remove particles deposited on coral branches, thus preventing smothering (Grange 1991, Stewart 1998). Grange (1991) also observed that corals associated with ophiuroids recovered faster from catastrophic events, such as landslides, than colonies that carried no ophiuroids.

In 2010, the Deepwater Horizon (DWH) blowout resulted in the release of approximately 4.9 million barrels of crude oil at a depth of $1500 \mathrm{~m}$ (McNutt et al. 2012). The first discovery of an impacted gorgonian community was made 3.5 mo after the well was capped. At this site, most colonies were at least partially covered in a brown flocculent material that contained traces of oil from the Macondo well (White et al. 2012a, Hsing et al. 2013). Subsequent work on material removed from the corals showed that it also contained dioctyl sodium sulfosuccinate, a compound diagnostic of the dispersant deployed during the spill (White et al. 2014). In 2011, 2 additional affected communities were discovered (Fisher et al. 2014). Like the community discovered first, these communities were dominated by the octocoral Paramuricea biscaya (Grasshoff, 1977), commonly associated with the euryalid ophiuroid Asteroschema clavigerum (Verrill, 1884). Little is known about these 2 species and the nature of their association. Interestingly, A. clavigerum was always observed on healthy parts of visibly impacted coral colonies, suggesting that ophiuroids were either avoiding impacted branches or protecting portions of the coral colony.

The goals of this study were to assess the impact of the DWH oil spill on ophiuroid associates, characterize the nature of the association between $A$. clavigerum and $P$. biscaya, and determine whether ophiuroids affected coral recovery, using image analysis. We hypothesized that ophiuroids protected their hosts from some adverse effects of the spill, and had a positive effect on coral recovery from impact.

\section{MATERIALS AND METHODS}

\section{Study sites and image acquisition}

We imaged corals at 4 sites in the northern Gulf of Mexico. The first impacted site discovered on 15 July 2010, in Bureau of Ocean Energy Management lease block Mississippi Canyon (MC) 294, was located $13 \mathrm{~km}$ from the well. The 2 additional impacted communities discovered in 2011, MC297 and MC344, were 6 and $22 \mathrm{~km}$ from the well, respectively. The last site, Atwater Valley (AT) 357, was located much farther away from the source of the oil spill (183 km), and coral colonies showed no evidence of recent impact.

The data reported here come from 7 research cruises conducted between 2010 and 2014 using remotely operated vehicles to obtain high-resolution images of the coral colonies. MC294 was the only site visited in 2010. During each visit, as many coral colonies as possible were imaged, and if the corals had been imaged before, every effort was made to obtain images from the same heading and camerasubject distance to allow a detailed analysis of changes in the corals and their symbionts between visits. Coral communities at the 3 impacted sites were dominated by Paramuricea biscaya, and more than half of the corals at these sites hosted 1 or more ophiuroids of the species Asteroschema clavigerum (Table 1). Corals present at AT357 were identified as 
Table 1. Total number of corals and number of corals hosting 1 or more ophiuroids at the 3 impacted sites and the reference site (AT 357) in 2011

\begin{tabular}{|lccc|}
\hline Site & $\begin{array}{c}\text { Total } \\
\text { corals } \\
\text { (n) }\end{array}$ & $\begin{array}{c}\text { Corals with } \\
\text { 1 ophiuroid } \\
\text { (n) }\end{array}$ & $\begin{array}{c}\text { Corals with } \\
>1 \text { ophiuroid } \\
\text { (n) }\end{array}$ \\
\hline MC294 & 49 & 25 & 8 \\
MC297 & 69 & 44 & 4 \\
MC344 & 25 & 12 & 0 \\
AT357 & 82 & 32 & 25 \\
\hline
\end{tabular}

Paramuricea sp. B3 and hosted at least 1 species of Ophiocreas in addition to A. clavigerum. Corals and their associates were identified in previous studies based on morphology and molecular barcoding (White et al. 2012a, Doughty et al. 2014). Experts were consulted for the identification of the ophiuroid species at AT357.

\section{Ophiuroid fidelity}

The number of ophiuroids on each coral colony was recorded during each visit. Loss of ophiuroids and the percentage of ophiuroids that stayed on the same coral between each visit (fidelity) were determined for all 4 sites. We used the presence of scars (regenerating arms) to identify individual ophiuroids when possible. When no identifying marks were present, we assumed that ophiuroids that were at the same location on the colony from one year to another were the same individuals. Differences in fidelity among sites and years were tested with Fisher's exact test.

\section{Relation between the presence of ophiuroids and level of impact}

Coral colonies were digitized using Inkscape 0.48.5 and branches coded as visibly impacted (excess mucus, bare skeleton, absence of polyps), colonized by hydroids, or not visibly impacted, based on the method described by Hsing et al. (2013). The level of total visible impact was calculated based on the proportion of branches either colonized by hydroids or otherwise visibly impacted in images from 2011. The mean level of total visible impact in corals that did not host any ophiuroids and in colonies that had at least 1 ophiuroid associate were compared for each site, and significant differences were tested with the non-parametric Mann-Whitney Wilcoxon test.

\section{Effect of impact on ophiuroid position on the colony}

Ophiuroids were normally located at the center of their host colony. To determine whether the position occupied by the ophiuroids on corals was altered by impact to the coral, a polygon was defined around each colony that supported 1 brittle star, and the position of its centroid was determined using ImageJ 1.48. For each coral colony, the distance between the centroid and the center of the ophiuroid oral disc was determined. This distance was then compared between corals that had a level of total visible impact over $20 \%$ of the colony and healthier corals (total visible impact lower than $20 \%$ ) using the MannWhitney Wilcoxon test.

\section{Determination of an area clearly under the influence of ophiuroids}

In order to further investigate the role of ophiuroids in providing some resilience to impact from the spill, we compared impact to a colony in areas clearly under the influence of the ophiuroid associate to the rest of the colony. To account for differences in arm length of different sized ophiuroids, we used the diameter of the ophiuroid's oral disc as our unit of measurement in these analyses. We first determined the maximum reach of the ophiuroids by measuring the length of the arms of 18 individuals for which that was possible using ImageJ 1.48. In most cases, all arms were too tightly coiled for this measurement, but among the 18 individuals that were measurable, the arm lengths ranged from 19 to 34 times the diameter of the oral disc with an average of 24.5 times the disc diameter. This suggests that, at least theoretically, ophiuroids could have an influence on an area with a diameter about 50 times the diameter of the oral disc on average. In a separate analysis, we determined a diameter of influence empirically for 7 coral colonies from MC294 by plotting the level of total visible impact as a function of distance from the oral disc. Again our unit of measurement was the diameter of the oral disc of the ophiuroid on the coral being analyzed. Circles of increasing diameters were defined around each brittle star, and the cumulative level of total visible impact within each circle was calculated and plotted as a function of circle diameter (Fig. 1A,B). For all colonies, the curves had a sigmoidal shape, the level of impact started at 0 and increased with distance from the oral disc until it reached an asymptote. Initially, a logistic regression 


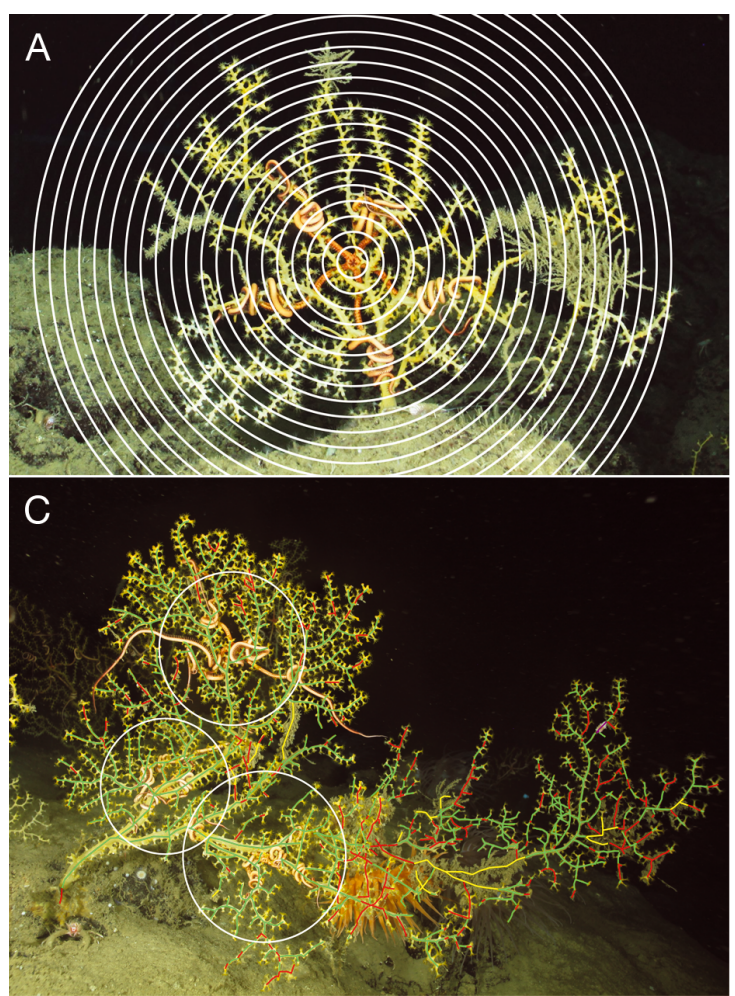

model was fitted to each curve, and the diameter of influence was defined where $99 \%$ of the value of the asymptote was reached (Fig. 1B). The average diameter of influence calculated using this method was equivalent to 36 times the diameter of the oral disc. In several cases, the perimeter of the circle approached the edge of the colony, and the comparison between impact inside and outside the area of influence was limited. In order to increase the robustness of this comparison, we used the diameter corresponding to half the value of the asymptote (19 times the oral disc diameter) to delineate areas under the influence of ophiuroids (Fig. 1C). We then compared impact to portions of coral colonies inside and outside of areas of ophiuroid influence as of October 2011, using both diameters, and corals from MC294 and MC297 using the Mann-Whitney Wilcoxon test. Coral colonies present at AT357 and MC344 were not analyzed because all corals were healthy at AT357, and not enough colonies could be used at MC344 (only $3 \mathrm{im}$ pacted colonies carrying ophiuroids were big enough to be analyzed).

\section{Ongoing effects of ophiuroids on coral colonies}

To track changes in state of portions of a colony between 2011 and 2014, the branch state in 2014 was

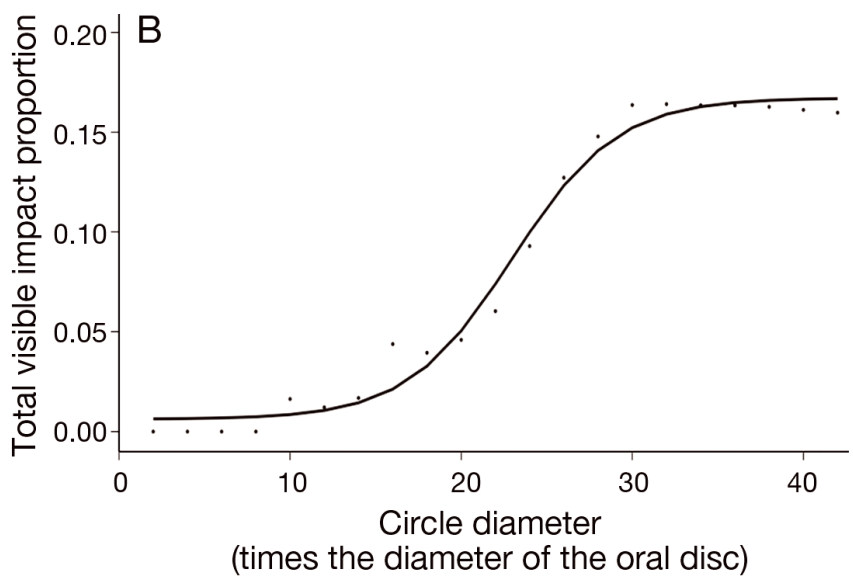

Fig. 1. (A) Determination of the area influenced by ophiuroids: example of a Paramuricea biscaya coral colony from site MC294. The first circle has a diameter equivalent to twice the diameter of the ophiuroid Asteroschema clavigerum oral disc, the second 4 times, and so on, until the entire colony is included. (B) Level of total visible impact and fitted logistic regression model as a function of the diameter of each circle. (C) Digitized image of a colony from MC297. Each circle has a diameter equivalent to 19 times the diameter of the ophiuroid oral disc

digitized on the 2011 images allowing a direct measurement of changing state. Changes in state of individual branches within and outside of the area of ophiuroid influence between 2011 and 2014 were compared using the Mann-Whitney Wilcoxon test. Ophiuroid positions on coral colonies from one year to another were very consistent, so the position of the oral disc in 2011 was used for this analysis.

In a separate analysis, the correlation between visible impact recovery or hydroid recovery and distance from the ophiuroid's oral disc (circles of increasing diameter) was measured for each colony using Spearman's rank correlation.

Non-parametric tests were used for all analyses because the data were not normally distributed, and none of the transformations we applied to the data sets resulted in normal distributions. Analyses were performed in Minitab® 17.2.1 and the R programming environment version 3.1.0 (R Core Team 2014).

\section{RESULTS}

About $70 \%$ of the corals at MC294, MC297, and AT357, and $50 \%$ at MC344 hosted at least 1 ophiuroid (Table 1). The proportion of corals hosting more than 1 brittle star varied among sites, with the highest proportion at AT357 (around 30\%) and the lowest 

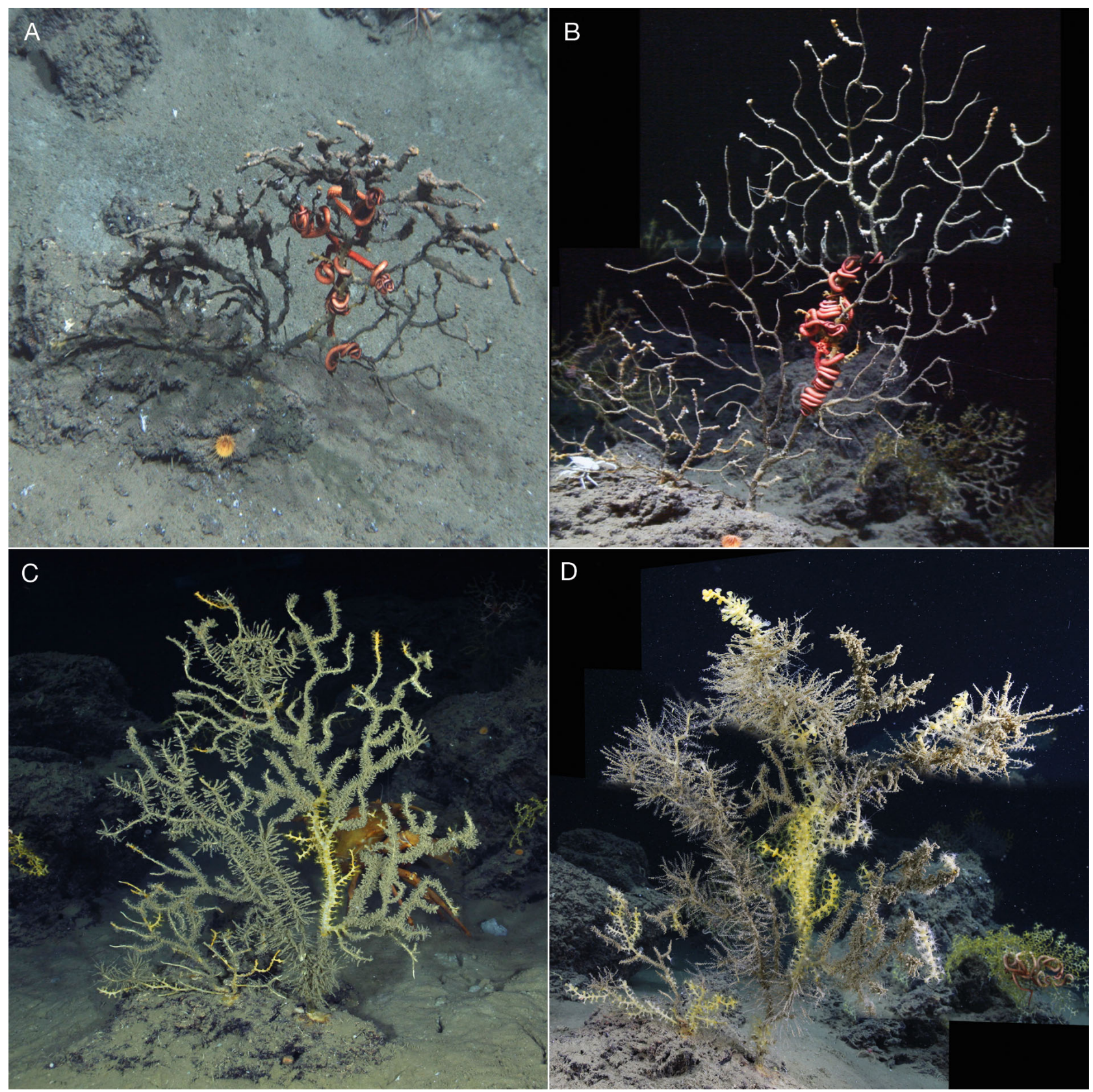

Fig. 2. Impacted Paramuricea biscaya coral colony from site MC294 imaged in (A) November 2010, (B) December 2010, (C) October 2011, and (D) June 2014. Note that the only healthy portion of the colony corresponds to the position of its ophiuroid Asteroschema clavigerum associate in 2010 (before it left the colony)

at MC344 (0\%). Larger colonies tended to host bigger brittle stars (simple linear regression model: $\mathrm{n}=$ 95 , intercept $=0.7524$, slope $=0.0003, \mathrm{R}_{\text {adj }}^{2}=0.2049, \mathrm{p}$ $<0.0001$ ), and the diameter of the ophiuroid oral disc ranged from 0.3 to $1.5 \mathrm{~cm}$ with an average of $0.89 \mathrm{~cm}$. Ophiuroids were always observed on healthy branches, with the exception of ophiuroids on corals where nearly $100 \%$ of the colony was impacted
(Fig. 2A). Most of the time they were in the central area of coral colonies, and were rarely observed near the base of the colony or on distal branches. The position of the arms often appeared to have changed from one year to another, while the oral disc was normally in the same area (the average movement of the oral disc between 2011 and 2014 was equivalent to $3.5 \pm 4.1$ times the diameter of the oral disc). Ophi- 


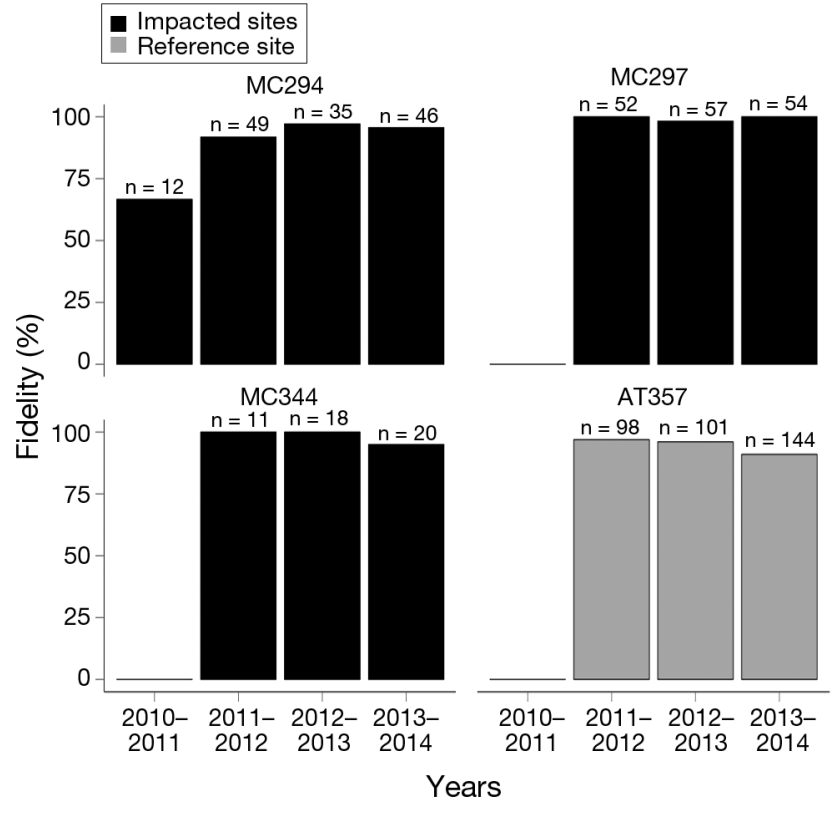

Fig. 3. Percentage of ophiuroids that stayed on the same coral from one year to another (fidelity) between 2010 and 2014 and between 2011 and 2014 at the 3 impacted sites and the reference site

uroids did not seem to avoid contact with the polyps. There were at least 2 species of ophiuroids present on Paramuricea sp. B3 at AT357: Asteroschema clavigerum and at least 1 species of Ophiocreas; at the other sites, $P$. biscaya was only associated with $A$. clavigerum.

Between 2011 and 2014, the percentage of ophiuroids that stayed on the same coral varied between 91 and $100 \%$, both at the impacted sites and at the reference site where none of the corals was visibly impacted by the spill (Fig. 3). At MC294, the first impacted site discovered, fidelity was significantly lower between 2010 and 2011 (Fisher's exact test, $\mathrm{p}=$ 0.007 ). Only $67 \%$ of the brittle stars imaged in the late 2010 visits were still clinging to their host in 2011.

At all 3 impacted sites, the mean level of total visible impact of coral colonies that were associated with a brittle star was significantly lower compared to coral colonies without clinging ophiuroids (MannWhitney Wilcoxon, MC294: $\mathrm{p}=0.0003$; MC297: $\mathrm{p}=$ 0.0096; MC344: $p=0.0015$; Fig. 4). We found no significant difference between corals with and without ophiuroids at the reference site (Mann-Whitney Wilcoxon, AT357: $\mathrm{p}=0.3072$ ), where the average level of total visible impact for both groups was about $1 \%$.

The average distance between ophiuroid oral discs and the center of their host colonies, estimated by

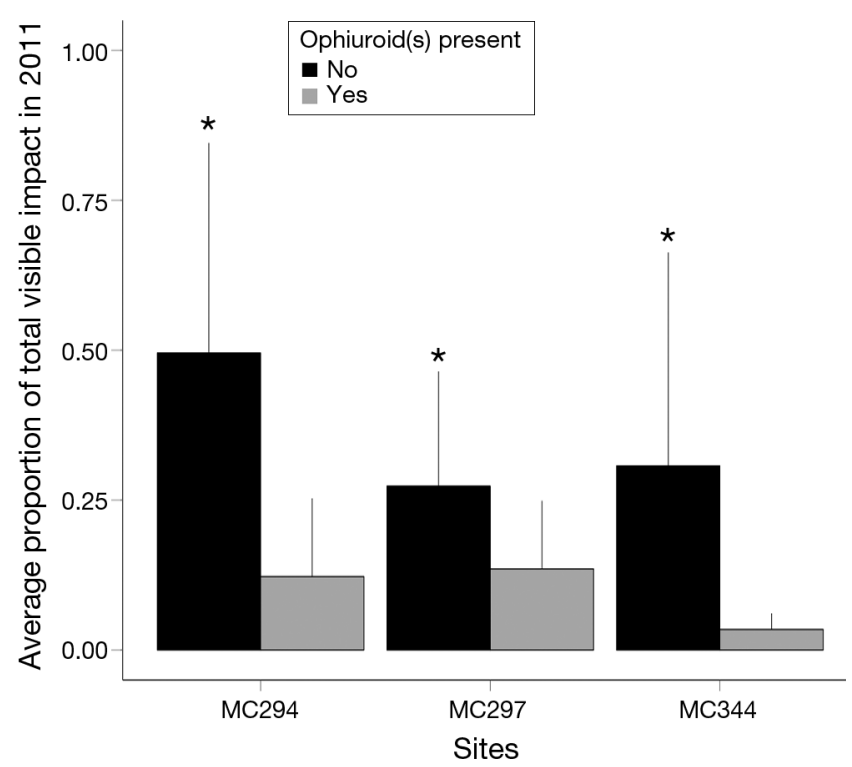

Fig. 4. Mean level of total visible impact of coral colonies associated or not associated with ophiuroids. The error bars represent the standard deviation. Differences were tested with the Mann-Whitney Wilcoxon test, and results were considered significant at $\mathrm{p}<0.05\left(^{*}\right)$

polygon centroids, was not significantly different between healthy and impacted colonies $(3.22 \pm 2.3$ [SD] $\mathrm{cm}$ and $5.09 \pm 4 \mathrm{~cm}$ away, respectively, Mann-Whitney Wilcoxon, $\mathrm{p}=0.327$ ).

The total level of visible impact was, on average, higher outside than inside the area influenced by ophiuroids, and this result was significant for MC297. We observed similar patterns at both sites of a higher proportion of changes to a more favorable state in areas influenced by ophiuroids than in areas outside that influence, although the differences were only significant in some cases (Fig. 5). The proportion of branches that changed from impacted to healthy was significantly higher inside than outside the area influenced by brittle stars for both sites (Mann-Whitney Wilcoxon, $\mathrm{p}<0.01)$. The same trends were observed when a larger diameter of influence was used for the analyses (Fig. A1 in the Appendix).

For 7 of 8 colonies at MC294 and 9 of 12 colonies at MC297, recovery from visible impact was significantly negatively correlated with distance from the ophiuroid oral disc (Table 2). For 2 of these corals, there was a significant positive relationship. No significant relationship was evident between recovery from visible impact and distance from the ophiuroid oral disc for the other 2 corals. We found no clear pattern for the relationship between branch recovery from hydroid colonization and distance from the ophiuroid oral disc (Table 2). 

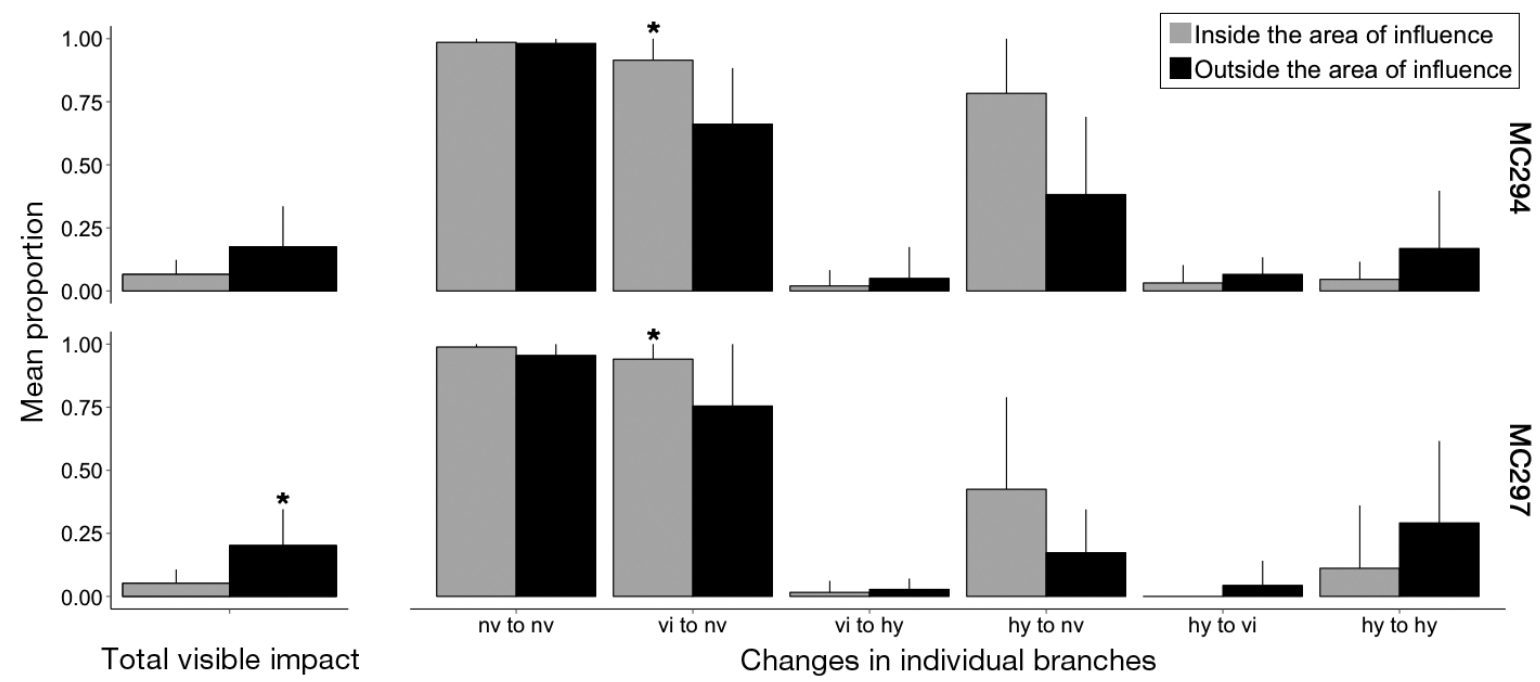

Fig. 5. Average level of total visible impact (site MC294: $\mathrm{n}=12$; site MC297: $\mathrm{n}=25$; only these 2 impacted sites were analyzed because not enough colonies were available for comparison at site MC344) and proportion of Paramuricea biscaya branches that changed from one category to another between 2011 and 2014 (nv: no visible impact, vi: visibly impacted, hy: hydroid colonization) inside and outside the area influenced by ophiuroids Asteroschema clavigerum (19 times the diameter of the oral disc) at both impacted sites. The error bars represent the standard deviation. Differences were tested with the Mann-Whitney Wilcoxon test, and results were considered significant at $\mathrm{p}<0.05\left(^{*}\right)$

Table 2. Spearman's rho correlation coefficients between visible impact recovery or hydroid recovery in colonies of Paramuricea biscaya and distance from the ophiuroid Asteroschema clavigerum oral disc (expressed as circle diameter). Only impacted sites MC294 and MC297 were analyzed because not enough colonies were available for comparison at impacted site MC344. Results were considered significant at $\mathrm{p}<0.05\left(^{*}\right)$. Blank cells: data not available

\begin{tabular}{|lccc|}
\hline $\begin{array}{l}\text { Coral } \\
\text { colony }\end{array}$ & Site & $\begin{array}{c}\text { Visible } \\
\text { impact recovery }\end{array}$ & $\begin{array}{c}\text { Hydroid } \\
\text { recovery }\end{array}$ \\
\hline A6 & MC294 & & -0.949 \\
B6 & MC294 & & $0.798^{*}$ \\
B9 & MC294 & $-0.949^{*}$ & $-0.756^{*}$ \\
C5 & MC294 & $-0.900^{*}$ & \\
D1 & MC294 & $-0.913^{*}$ & \\
D5 & MC294 & $-0.873^{*}$ & \\
F2 & MC294 & $-0.790^{*}$ & \\
F3 & MC294 & $-0.895^{*}$ & $-1.00^{*}$ \\
F5 & MC294 & $0.615^{*}$ & \\
M3-6 & MC294 & $-0.842^{*}$ & \\
M3-8 & MC297 297 & $0.642^{*}$ & -0.400 \\
M3-11 & MC297 & $-0.841^{*}$ & \\
M3-13 & MC297 & $-0.767^{*}$ & 0.095 \\
M3-17 & MC297 & $-0.889^{*}$ & \\
M3-18 & MC297 & $-0.876^{*}$ & $-0.974^{*}$ \\
M6-9 & MC297 & $-0.969^{*}$ & \\
MM1-1 & MC297 & $-0.366^{*}$ & \\
MM1-9 & MC297 & $-0.431^{*}$ & \\
MM1-17 & MC297 & $-0.684^{*}$ & \\
MM1-18 & MC297 & $-0.087^{*}$ & -0.667 \\
MM1-32 & MC297 & $-0.431^{*}$ & $-0.975^{*}$ \\
MM1-40 & MC297 & $-0.952^{*}$ & \\
\hline
\end{tabular}

\section{DISCUSSION}

The majority of coral colonies at each site were associated with at least 1 ophiuroid. Coral colonies at AT357 sometimes carried several ophiuroids of different species, indicating a more general association between ophiuroids and Paramuricea sp. B3 at this site. Conversely, $P$. biscaya was only associated with 1 species, Asteroschema clavigerum, at the other sites. Ophiuroids generally had their arms tightly coiled around coral branches and in some instances were clearly touching extended polyps. This type of interaction was observed with other species and suggests that the presence of the brittle star does not adversely affect the coral host and vice versa (Emson \& Woodley 1987, Fujita \& Ohta 1988, Grange 1991). Analyses of the stomach contents of obligate ophiuroid species have shown that ophiuroids do not feed on polyps, and no damage due to ophiuroids has been found on corals (Emson \& Woodley 1987, Grange 1991).

At all sites, ophiuroid fidelity after 2011 was close to $100 \%$. High fidelity between an ophiuroid and a coral has been previously documented (Mosher \& Watling 2009). The asteroschematid ophiuroid Ophiocreas oedipus spends its entire life attached to the octocoral Metallogorgia melanotrichos. Very small $O$. oedipus have been found clinging to juvenile $M$. melanotrichos, suggesting that the ophiuroids may directly settle on the corals (Mosher \& Watling 2009). The fact that we observed 4 very small $A$. clavigerum 
on 3 different corals suggests that this species may also settle directly on $P$. biscaya. New adult individuals were observed between 2011 and 2014 on some colonies, indicating occasional movement of brittle stars between colonies. The largest number of new adult ophiuroids was observed at AT357 (15 new ophiuroids), where coral density is high, with many corals directly adjacent to one another. Ophiuroid migrations were also documented at MC294, with 7 newly established brittle stars documented over $4 \mathrm{yr}$. In 1 instance, a brittle star moving from one colony to another was observed. Considering the scarcity of coral communities, and the fact that the number of ophiuroids that appeared between 2011 and 2014 was always smaller than the number of ophiuroids that were lost, it is likely that the newly established ophiuroids came from other colonies within the same site. Between 2010 and 2011, 4 ophiuroids left their host at MC294. Three of the 4 ophiuroids that were lost between 2010 and 2011 were initially on heavily impacted corals (see Fig. 2 for an example). When MC294 was discovered a few months after the Macondo well was capped, White et al. (2012a) observed that only $47 \%$ of the A. clavigerum associated with $P$. biscaya had a normal color (tan to red); the rest had distinctly white arms or were completely bleached. They also noted that several ophiuroids had their arms loosely coiled around coral branches, an abnormal behavior for this species. This suggests that A. clavigerum was likely directly impacted like the corals (White et al. 2012a), either through surface exposure to oil and/or dispersant or by ingesting contaminated particles or zooplankton (Mitra et al. 2012); this raises the possibility that some individuals died or left their host during the following year.

On average, A. clavigerum had a beneficial effect on its $P$. biscaya host over an area equivalent to at least 19 times the diameter of its oral disc. At MC297, the total visible level of impact was significantly lower in the area influenced by ophiuroids than in the rest of the colony. Ophiuroid presence was correlated with a general trend of enhanced recovery from impact and from hydroid colonization over a $3 \mathrm{yr}$ period, although these trends were not always significant for hydroids. Moreover, corals that carried 1 or more ophiuroids were on average less visibly impacted than corals that did not host any. These results, coupled with the fact that the position of ophiuroids within colonies was not affected by the presence of impact, suggest that A. clavigerum did not avoid impacted branches. In other words, the correlation between ophiuroid position and healthy coral tissue was not a result of the ophiuroid moving into that area. Rather, the ophiuroids had a positive influence on the ability of $P$. biscaya to avoid visible damage from the effects of the DWH spill over areas of the colony under their influence, and also aided in recovery from this impact. Previous studies have concluded that the ophiuroid-coral association primarily benefits the ophiuroids by providing them with structure above the sea floor with enhanced access to food in the epibenthic water (Emson \& Woodley 1987, Fujita \& Ohta 1988). Our observations support those of Grange (1991), who observed that corals supporting ophiuroids were more likely to recover after catastrophic events such as landslides due to a positive influence of ophiuroids on their coral hosts. Our study also suggests that ophiuroids, in addition to protecting their coral host from sedimentation events, can enhance coral recovery after anthropogenic damage. Hsing et al. (2013) documented the onset of hydroid colonization on impacted portions of coral colonies $1 \mathrm{yr}$ after the DWH oil spill. Subsequently, overall hydroid colonization tended to increase over time. We demonstrated that the presence of ophiuroids had a positive effect on coral recovery from hydroid colonization, perhaps by removing hydroid colonies and preventing further settlement.

Understanding the interaction between all members of deep-sea communities is important to better assess recovery potential after anthropogenic impacts. As developing technology facilitates anthropogenic activities at ever greater ocean depths, the potential for impact to virtually all deep-sea ecosystems is increasing (Ramirez-Llodra et al. 2011). Deepwater corals are particularly vulnerable to bottom trawling (Koslow et al. 2001, Fosså et al. 2002, HallSpencer et al. 2002), other fishing activities (Clark \& Koslow 2008, Fisher et al. 2014), and increasing oil extraction and mining activities (Clark et al. 2010, White et al. 2012a, Hsing et al. 2013, Fisher et al. 2014). Because of their slow growth rates (Andrews et al. 2002, Roark et al. 2009), recovery and regrowth of deep-sea corals damaged or killed by anthropogenic activities will take decades to centuries. Moreover, our study highlights the consequences of the destruction of deep-water coral assemblages on biodiversity. A. clavigerum, as well as other organisms, depend entirely on corals for their survival and would not persist in the absence of their host.

\section{CONCLUSIONS}

In addition to impact on corals, there was a loss of commensal ophiuroids associated with the DWH oil 
spill. It seems that ophiuroids did not preferentially move to healthy portions of the colony after impact, but instead, protected the branches they were attached to (e.g. see Fig. 2A-C). These branches remained healthy throughout the study period, even long after some ophiuroids left their hosts, indicating a lasting effect of these associates (e.g. Fig. 2D). Ophiuroids not only help protect their hosts from sedimentation or deposition of deleterious material on their surface, but also have a positive effect on coral recovery after impact. Asteroschema clavigerum uses Paramuricea biscaya to rise above the sea floor and get better access to food while its host reaps the benefits of the 'cleaning' behavior of the ophiuroid. Coral colonies associated with ophiuroids were less impacted by the DWH oil spill, and impacted branches were more likely to recover in the years following the spill. This association is a clear example of mutualism and demonstrates how symbiosis can significantly increase the partners' resilience to anthropogenic impact.

Acknowledgements. We thank the crews of the ships and deep submergence vehicles used for this study. We also thank I. MacDonald for providing the digital still camera in 2011 and T. Shank and W. Cho for their help with species identification. Additional thanks to S. Vohsen, R. Dannenberg, J. Mentch, M. Kurmann, D. McKean, and S. Berlet for their support at sea and in the lab, and to K. Shea, T. LaJeunesse, and I. Baums for valuable inputs to the analyses. This research was made possible by a grant from the Gulf of Mexico Research Initiative. Data are publicly available through the Gulf of Mexico Research Initiative Information and Data Cooperative (GRIIDC) at https://data.gulfresearch initiative.org (doi: <10.7266/N7NG4NJP $>_{,}<10.7266 /$ N7HQ $3 W V D>, \quad<10.7266 /$ N7D21VJQ $>, \quad<10.7266 /$ N78913TC $>$, $<10.7266 /$ N74J0C2M>). This is contribution no. 373 from the Ecosystem Impacts of Oil and Gas Inputs to the Gulf (ECOGIG) consortium.

\section{LITERATURE CITED}

Andrews AH, Cordes EE, Mahoney MM, Munk K, Coale KH, Cailliet GM, Heifetz J (2002) Age, growth and radiometric age validation of a deep-sea, habitat-forming gorgonian (Primnoa resedaeformis) from the Gulf of Alaska. Hydrobiologia 471:101-110

Baillon S, Hamel JF, Wareham VE, Mercier A (2012) Deep cold-water corals as nurseries for fish larvae. Front Ecol Environ 10:351-356

Bronsdon SK, Tyler PA, Rice AL, Gage JD (1993) Reproductive biology of two epizoic anemones from the deep north eastern Atlantic Ocean. J Mar Biol Assoc UK 73:531-542

Buhl-Mortensen L (2004) Symbiosis in deep-water corals. Symbiosis 37:33-61

Buhl-Mortensen L, Mortensen PB (2004) Crustaceans associated with the deep-water gorgonian corals Paragorgia arborea (L., 1758) and Primnoa resedaeformis (Gunn.,
1763). J Nat Hist 38:1233-1247

Buhl-Mortensen L, Mortensen PB (2005) Distribution and diversity of species associated with deep-sea gorgonian corals off Atlantic Canada. In: Freiwald A, Roberts JM (eds) Cold-water corals and ecosystems. Springer, Berlin, p 849-879

Buhl-Mortensen L, Vanreusel A, Gooday AJ, Levin LA and others (2010) Biological structures as a source of habitat heterogeneity and biodiversity on the deep ocean margins. Mar Ecol (Berl) 31:21-50

Clark MR, Koslow JA (2008) Impacts of fisheries on seamounts. In: Pitcher TJ, Morato T, Hart PJB, Clark MR, Haggan N, Santos RS (eds) Seamounts: ecology, fisheries \& conservation. Blackwell publishing, Oxford, p 413-441

Clark MR, Rowden AA, Schlacher T, Williams A and others (2010) The ecology of seamounts: structure, function, and human impacts. Annu Rev Mar Sci 2:253-278

Dearborn JH, Ferrari FD, Edwards KC (1986) Can pelagic aggregations cause benthic satiation? Feeding biology of the Antarctic brittle star Astrotoma agassizii (Echinodermata: Ophiuroidea). Antarct Res Ser 44:1-28

Doughty CL, Quattrini AM, Cordes EE (2014) Insights into the population dynamics of the deep-sea coral genus Paramuricea in the Gulf of Mexico. Deep-Sea Res II 99: 71-82

> Emson RH, Woodley JD (1987) Submersible and laboratory observations on Asteroschema tenue, a long-armed euryaline brittle star epizoic on gorgonians. Mar Biol 96: $31-45$

Etnoyer P, Warrenchuk J (2007) A catshark nursery in a deep gorgonian field in the Mississippi Canyon, Gulf of Mexico. Bull Mar Sci 81:553-559

> Fisher CR, Hsing PY, Kaiser CL, Yoerger DR and others (2014) Footprint of Deepwater Horizon blowout impact to deep-water coral communities. Proc Natl Acad Sci USA 111:11744-11749

> Fosså JH, Mortensen PB, Furevik DM (2002) The deepwater coral Lophelia pertusa in Norwegian waters: distribution and fishery impacts. Hydrobiologia 471:1-12

> Fujita T, Ohta S (1988) Photographic observations of the life style of a deep-sea ophiuroid Asteronyx loveni (Echinodermata). Deep-Sea Res A Oceanogr Res Pap 35: 2029-2043

Grange KR (1991) Mutualism between the antipatharian Antipathes fiordensis and the ophiuroid Astrobrachion constrictum in New Zealand fjords. Hydrobiologia 216217:297-303

> Hall-Spencer J, Allain V, Fosså JH (2002) Trawling damage to Northeast Atlantic ancient coral reefs. Proc R Soc B 269:507-511

> Henry LA, Roberts JM (2007) Biodiversity and ecological composition of macrobenthos on cold-water coral mounds and adjacent off-mound habitat in the bathyal Porcupine Seabight, NE Atlantic. Deep-Sea Res I 54: 654-672

> Hsing PY, Fu B, Larcom EA, Berlet SP and others (2013) Evidence of lasting impact of the Deepwater Horizon oil spill on a deep Gulf of Mexico coral community. Elem Sci Anthropocene 1:000012

> Koslow JA, Gowlett-Holmes K, Lowry JK, O'Hara T, Poore GCB, Williams A (2001) Seamount benthic macrofauna off southern Tasmania: community structure and impacts of trawling. Mar Ecol Prog Ser 213:111-125

Mah C, Nizinski M, Lundsten L (2010) Phylogenetic revision of the Hippasterinae (Goniasteridae; Asteroidea): sys- 
tematics of deep sea corallivores, including one new genus and three new species. Zool J Linn Soc 160:266-301

McNutt MK, Camilli R, Crone TJ, Guthrie GD and others (2012) Review of flow rate estimates of the Deepwater Horizon oil spill. Proc Natl Acad Sci USA 109:20260-20267

Mitra S, Kimmel DG, Snyder J, Scalise K and others (2012) Macondo-1 well oil-derived polycyclic aromatic hydrocarbons in mesozooplankton from the northern Gulf of Mexico. Geophys Res Lett 39, L01605, doi:10.1029/2011 GL049505

Mosher CV, Watling L (2009) Partners for life: a brittle star and its octocoral host. Mar Ecol Prog Ser 397:81-88

Pentreath RJ (1970) Feeding mechanisms and the functional morphology of podia and spines in some New Zealand ophiuroids (Echinodermata). J Zool 161:395-429

R Core Team (2014) A language and environment for statistical computing. R Foundation for Statistical Computing, Vienna

Ramirez-Llodra E, Tyler PA, Baker MC, Bergstad OA and others (2011) Man and the last great wilderness: human impact on the deep sea. PLoS One 6:e22588

Roark EB, Guilderson TP, Dunbar RB, Fallon SJ, Mucciarone
DA (2009) Extreme longevity in proteinaceous deep-sea corals. Proc Natl Acad Sci USA 106:5204-5208

Roberts JM, Wheeler AJ, Freiwald A (2006) Reefs of the deep: the biology and geology of cold-water coral ecosystems. Science 312:543-547

Stewart B (1998) Can a snake star earn its keep? Feeding and cleaning behaviour in Astrobrachion constrictum (Farquhar) (Echinodermata: Ophiuroidea), a euryalid brittle-star living in association with the black coral, Antipathes fjordensis (Grange, 1990). J Exp Mar Biol Ecol 221:173-189

Warner G (1982) Food and feeding mechanisms: Ophiuroidea. In: Jangoux M, Lawrence JM (eds) Echinoderm nutrition. A.A. Balkema, Rotterdam, p 161-181

White HK, Hsing PY, Cho W, Shank TM and others (2012a) Impact of the Deepwater Horizon oil spill on a deepwater coral community in the Gulf of Mexico. Proc Natl Acad Sci USA 109:20303-20308

White HK, Lyons SL, Harrison SJ, Findley DM, Liu Y, Kujawinski EB (2014) Long-term persistence of dispersants following the Deepwater Horizon oil spill. Environ Sci Technol Lett 1:295-299

\section{Appendix}

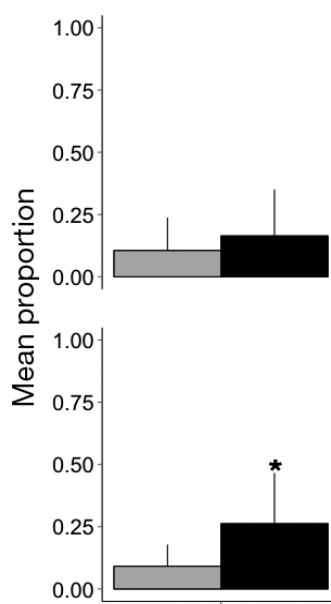

Total visible impact
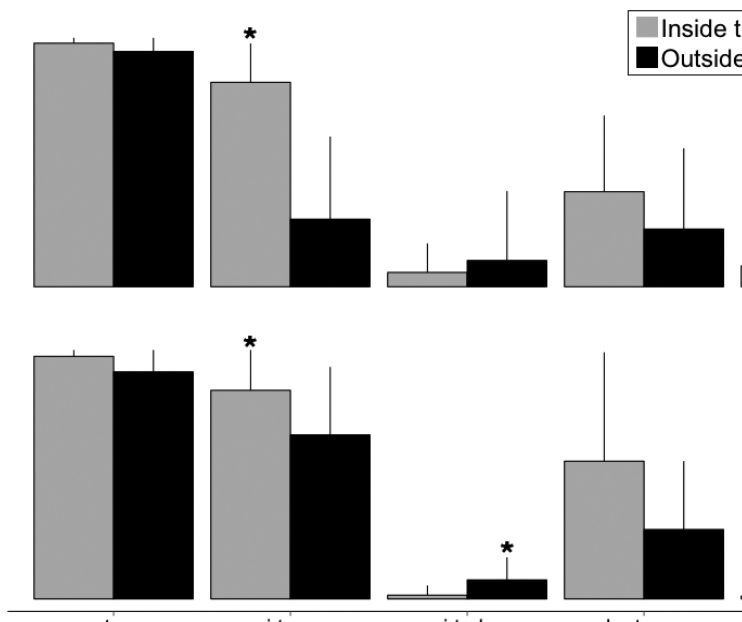

hy to nv

Changes in individual branches

the area of influence

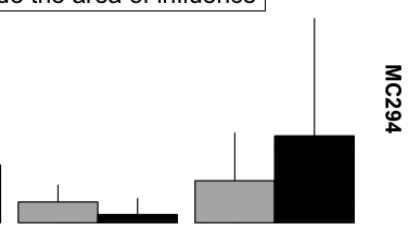

\section{(1)}

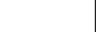

Fig. A1. Average level of total visible impact (site MC294: $\mathrm{n}=9$; site MC297: $\mathrm{n}=18$; only these 2 impacted sites were analyzed because not enough colonies were available for comparison at site MC344) and proportion of Paramuricea biscaya branches that changed from one category to another between 2011 and 2014 (nv: no visible impact, vi: visibly impacted, hy: hydroid colonization) inside and outside the area influenced by ophiuroids Asteroschema clavigerum (36 times the diameter of the oral disc) at both impacted sites. The error bars represent the standard deviation. Differences were tested with the Mann-Whitney Wilcoxon test, and results were considered significant at $\mathrm{p}<0.05\left({ }^{*}\right)$

Editorial responsibility: Karen Miller,

Hobart, TAS, Australia
Submitted: November 19, 2015; Accepted: March 14, 2016

Proofs received from author(s): April 18, 2016 